\title{
WITHDRAWN: Commentary: The mechanics, semantics, and "echonomics" of myocardial recovery on pediatric ventricular assist device therapy
}

\author{
Ronald K. Woods, MD, PhD
}

Division of Pediatric Cardiothoracic Surgery, Department of Surgery, Medical College of Wisconsin, Milwaukee, Wis

Herma Heart Institute, Children's Hospital of Wisconsin, Milwaukee, Wis

This article has been withdrawn at the request of the author(s) and/or editor. The Publisher apologizes for any inconvenience this may cause.

The full Elsevier Policy on Article Withdrawal can be found at https://www.elsevier.com/about/ourbusiness/policies/article-withdrawal 